\title{
Highs and Lows of Implementing a Management Strategy Eliminating 'Free Passengers' in Group Projects
}

\section{Marilyn Ford \\ Griffith University, Logan, Queensland, Australia}

m.ford@griffith.edu.au

\author{
Tony Jewels \\ Queensland University of \\ Technology, Brisbane, \\ Queensland, Australia
}

\author{
t.jewels@qut.edu.au
}

\begin{abstract}
In attempting to give students the opport unity to work on group projects with other students, yet ensuring students receive the marks that they each deserve, a management strategy for dealing with group work initially proposed by Ford and Morice (2003) was implemented. The present paper discusses the implementation of this strategy with its positive and negative outcomes. While good students were, not surprisingly, happy to receive the marks they deserved and while some of the benefits of group work were gained, there were problems that led to resentment and hostility from some students. Suggestions for improving the strategy and an initial attempt to implement the revised strategy are also discussed.
\end{abstract}

Keywords: group projects, assessment

\section{Introduction}

It is now well established that the IT industry, along with possibly every other industry, wants graduates who are able to work effectively in groups, and many university courses are consequently now using group projects. Benefits of group work are said to include: higher order thinking (Cohen, 1994), increased communication and conflict management skills (Johnson \& Johnson, 1996; Williams, Beard, \& Rymer, 1991), as well as skills in teamwork, time management, and interpersonal relationships (Koppenhaver \& Shrader, 2003). It has also been noted that students with limited skills can learn from those with greater skills (Van Der Vyver \& Lane, 2003). Unfort unately, it is also known that group projects can lead to a plethora of problems (Hansen \& Hansen, 2007). The "free passenger" syndrome is recognised as a major problem; with some students putting in little effort, causing stress to other team members yet, despite doing little or no work, receiving the same mark as other team members (Ford \& Morice, 2003; Hasan \& Ali,

Material published as part of this publication, either on-line or in print, is copyrighted by the Informing Science Institute. Permission to make digital or paper copy of part or all of these works for personal or classroomuse is granted without fee provided that the copies are not made or distributed for profit or commercial advantage AND that copies 1) bear this notice in full and 2) give the full citation on the first page. It is permissible to abstract these works so long as credit is given. To copy in all other cases or to republish or to post on a serveror to redistribute to lists requires specific permission and payment of a fee.Contact Publisher@ InformingScience.org to request redistribution permission.
2007). Academics might claim they are simulating a "real world" environment, but as one student noted in a survey by Ford \& Morice, "they try to be like the real world but they're really not."

One difference between the real world and typical group projects at university is that team members who do not perform in the real world may be identified and dismissed by the supervisor; the 
supervisor can see what is happening and has the power to do something about the problem. With university project groups, academics are often not aware that someone is not working, until another group member alerts them. To help overcome the problem, Ford \& Morice put forward a management strategy for running group projects at university. This paper discusses an attempt to implement the management strategy, which we will for convenience call the Monit ored Group (MG) strategy. It will be seen that some aspects of the strategy were not possible to implement (or at least it was realised that such implementation could lead to serious problems). It will also be seen that, as hoped, many students were very relieved and thankful that finally their work was being recognised but that, unexpectedly, some students still became quite resentful and hostile.

\section{The MG Strategy and Its Implementation}

Ford \& Morice (2003) wanted to provide a strategy that would provide conditions that were more similar to those found in the real world. They thus developed a three-phase strategy using management techniques on a small scale:

"(1) the initiation phase where an academic staff member, who acts as a "group manager," advertises positions on projects, students apply forthe positions, and appointments are made;

(2) the management phase where the "group manager" and each group meet according to an agreed schedule and where group members work according to contracts; and

(3) the completion phase where a "post-mortem" and individual marking (not group marking) takes place. (Ford \& Morice, 2003, p.367)"

The course chosen for implementation of the strategy was a course on user interface design; a second year 13-week course with approximately 150 students separated into 5 laboratory classes. Students were initially briefed about how the group work would proceed in the course. No students complained and, in fact, some seemed very happy about the strategy.

\section{The Initiation Phase}

Students were asked, for their first assignment, to write a résumé that was laid out using certain design principles. Given that the course was on user interface design, this assignment was quite appropriate. Students were asked not to include their real Grade Point Average and were advised that their mark would depend on the layout of the résumé, not the content. The idea, they were told, was that students would be grouped according to how well they laid out their résumé, not on how well they had performed in the past. This concept was in line with Ford \& Morice's proposal: "The aim of the initiation phase is to divide the class into effective groups that will work together well and that consist of members who are somewhat comparable in terms of effort they are likely to put in and where students are treated equally regardless of the position in the "social structure' of the class (Ford \& Morice, 2003, p.374)."

Students submitted their work and it became immediately clear that there were problems with this plan for organizing students into groups. First, there were quite a few students who handed in work that was totally unacceptable, whether through lack of care or lack of ability or understanding or problems with English. To form whole groups consisting of these individuals would probably have spelled disaster for all members. While that might be justified for many of the members, it was realised that some students may indeed have tried and been motivated and might even be able, if given the right circumstances, be able to improve throughout the semester. Second, it was realised that if students were grouped according to the mark they obtained, then students would be able to work out what kind of mark other students in their group had obtained. While the course outline had indicated how groups would be organised and had been approved and while no students had complained about the proposal, the fear of students complaining about 
other people being able to work out their mark was real. Third, while some students submitted unacceptable work, the work of many other students was quite comparable and did not provide a good basis for organizing groups anyway.

It was decide d that students would be placed into groups randomly, though making sure each group consisted of people in the same laborat ory class. Each group consisted of $4-5$ people. Making sure people were in the same laboratory group helped lessen the possibility of timetable clashes of group members, a feature in line with the ideas of Ford \& Morice (2003). Students were informed that the groups were being formed randomly and were told that many students had written work of comparable standard, thus providing little basis for grouping.

\section{The Management Phase}

Ford \& Morice (2003) noted that the major aim of the management phase was to create good information flow between the academic and each group: "It should ensure that the staff member is very well informed of who is doing what. It should also give the students clear guidelines of what is expected of them as valuable group members" (Ford \& Morice, 2003, p.375). According to Ford \& Morice's strategy, students would agree on, and sign, work contracts and would out a schedule of meetings, with time sheet s kept. They noted that their strat egy "should ... provide a forum for students to admit the existence of conflicts and attempt to reach a resolution" (Ford \& Morice, 2003, p.375-356). According to their proposed strategy, "Where a student does not keep to a contract the Group Manager should 'dismiss' the student, replicating what would happen in industry - in this sit uation the student could be required to do a project by themselves and be penalised $10 \%$. This would help alleviate the problem that some students noted - that unlike in real industry the noncontributors cannot be 'sacked'" (Ford \& Morice, 2003, p.375- 356).

From the out set, one modification was made to the strategy proposed by Ford \& Morice (2003). While groups were to meet with the staff member at the end of most laboratory classes to discuss the progress of the group work, there were no contracts signed. It seemed somewhat burdensome to do this and with students' busy schedules; it was not clear how realistic a set contract would be.

It was certainly true that the academic did feel that by meeting with groups most weeks, it was more apparent than usual who was working and who was not; that is, information flow did seem to increase. Of course, there were no doubt groups where some problems were not identified, but at least the academic had a better grasp of who was turning up to meetings and could see, first hand, during explanations of what was being done, who seemed to know what was happening. It was also clear, though, that information flow was not as good as had been hoped.

One problem was that some groups never admitted that there were any problems and yet it was clear that there were. Typically, these groups would cope with underperformers by some members doing what they felt should be done and letting the others who were not so eager just do what they wanted to do. It was almost as though some groups were acting as two groups. Presumably the groups, under normal circumstances, would simply end up putting all group members' names on the submit ted (presumably best, most complete) product. While non-workers or under-workers were initially meant to be split from the group, do the project themselves, and incur a $10 \%$ penalty, this did not in the end seem appropriate. The main problem was that group members often seemed to have different ideas about what constituted reasonable effort. It did not seem right to penalise people in a group that had in it a high achiever who was doing a lot more work than the others. Fortunately, in all the groups that seemed to have basically two subgroups working separately, each subgroup consisted of at least two students. In all the cases identified, the groups were split into two by the academic, but with no penalty incurred. 
There were some groups that did complain about other group members, but again it did not, in the end, seem appropriate to give a $10 \%$ penalty to any student. The problem was that one could say that whether anyone complained about you or not was more a function of who was in your group. Thus, if you were an underachiever but working with students who kept complaints to themselves, you might be lucky, but if you were with students not willing to complain, you would be lucky. Again, it was fort unate that in groups where there were complaints about members, there was always at least two 'workers' and two 'non-workers', so these groups could also be split into two groups by the academic, with no penalty incurred.

Goffee \& Jones's (1998) idea that an organization's culture could be analysed in terms of its 'sociability' (the need to have good relationships with other people) and its 'solidarity' (the need to concentrate on the task at hand) was clearly evident. Some group members appeared to be more concerned about keeping good relationships with other team members whereas others cared predominantly about the task at hand.

\section{The Completion Phase}

In line with the proposed strategy of Ford \& Morice (2003), there were only individual marks given to students; there was no 'group mark'. Each group gave an oral presentation on their work, focussing on the rationale for design decisions for their interface and on usability testing of the interface. All members were required to speak and each person was given their own individual mark for their presentation. Each student also had to submit an individual report on the group project, again focussing on the rationale for design decisions and usability testing. There were two groups who had, near the end of semester, pointed out that one of their member's was not working as expected. The group members were told them it was too late for the student to be asked to do a project by themselves, but that their lack of input would probably be reflected in their presentation and report. One of these students did not do a presentation or report, and hence received zero marks. The other did a presentation and report but, knowing little about the rationale for the design decisions, did poorly. There were no groups where all members achieved the same marks for their assessment relating to the group project. The range of marks for individuals in groups could, and did, range from fail to high distinction. There was one group where a request was made by group members to increase another member's mark because they felt his poor performance was partly due to them not getting him something on time ... and this mark was consequently increased. The awarding of individual marks for a group presentation about the project and an individual report seemed to work well and there were no complaints with the final marks given.

\section{Assessment of the Management Strategy}

It should already be clear that there was an obvious need to modify the strategy once an attempt was made to implement it, yet at the same time it did lead to some positive outcomes. Student feedback was given spontaneously, but was also obtained by an email asking for feedback and a normal university administered survey. The feedback from students highlighted further positive and negative feat ures.

\section{The Positives}

\section{Fair marks}

It was clear from student feedback that the students felt that marking was fairer under the MG strategy. One student summed up her feeling well, saying: 
"It was very rewarding to receive a mark that I was proud of because I knew the work ... it finally feels as though you can receive what you deserve"

Another said he believed the marking for this course was the best way to proceed:

"I believe your marking for [this course] was the best. At the same time I was doing another course with a bigger group and our entire group mark was brought down partially due to the lack of participation of some members"

\section{Greater understanding of groups by the academic}

A number of students made it clear that they appreciated the fact that the academic had a good grasp of what was happening and felt that the group monitoring went well. Thus, one student said his group was happy with how the group was monitored and added:

"I have not heard other students complain that they were unhappy with the handling of their group situations"

The groups who showed most appreciation were those with members who were not considered to be pulling their weight. In some cases where there was a complaint and the students were split into two groups, the complaining students said a relieved "thank you". More importantly, thanks were given by a high achieving student who was part of a group where a complaint had not been made but where the academic had recognised that there was a problem and split the group. This student noted that the academic was "tuned in" to what was going on and said:

"I did not actually complain but thankfully you were able to see the problem and split our group”

\section{Less student stre ss}

There were some groups who did not complain about others for not pulling their weight until it was too lateto split groups. These students seemed to have trouble believing that the "nonworking" student would really get a different mark from them. This appeared to cause them stress. However, once they were finally convinced that the student could indeed get a different mark and were unlikely to do well since they knew virtually nothing about the project, they expressed great relief. Of course, hard working students who did complain about students who wished to work less and who were split from the others were also under less stress than they would have been if groups had remained intact.

\section{Help given by very able students to less able students}

It is possible that this positive feature is not attributable to the MG strategy per se, but to having groups that consist of people of markedly differing abilities, though with a willingness by all to work hard. It was very apparent that some groups had one or two students who were very competent and understood what was required to do a very good project. Where the other team members were less able, but were willing to work, the better students were sometimes able to 'lift the game' of the less able students, partly by continuing to insist that they wanted a High Distinction and that everyone need to do more. For at least some of these groups, the close monitoring by the academic helped. In these cases, the academic, on realising the very different levels of competency, was able to suggest ways different individuals could contribute. In these cases, the good students were pleased because they could see how the other students could 'add value' and the 
other students seemed to have a sense of achievement. While it is hard to prove they had a sense of achievement, it was easy to see their pleasure in what they had done by their smiles. Van Der Vyver and Lane (2003) have also noted that with group work, students with limited skills can learn from those with greater skills. It would seem that the MG strategy can facilitate this effect. Then projects were one the whole betterthan normally expected.

\section{The Negatives}

\section{Resentment of the monitoring}

One student wrote on an evaluation that he resented the monitoring of the groups, saying he felt they were treated like children that had to be constantly monitored. Another student stated that students should be allowed to choose their own groups and sort out their own problems rather than have the academic 'harassing' them to monitor whether people were putting in an equal share.

\section{Resentment for being split from a larger group}

One student wrote on an evaluation that he got a shock when he and his friend were split from a larger group because, as he put it, in other courses you never get taken out of a group even if you are not doing any work! Although the remark is possibly (or should be) an embarrassment for other courses, the resentment is still real and certainly a negative outcome of the MG strategy, at least as implemented here. While some students were very pleased and relieved that they could become a subgroup and no longer had to work with the larger group, others greatly resented the forced split. Interestingly, it was always the students considered to be hard working who were happy with the split and the less hard working who were unhappy. This is true even though the students did not incur a penalty and even when it was not made obvious by the academic who was considered not to be pulling their weight (where one could also say that there were really two subgroups operating anyway). Yet, pragmatically, having an environment where students are resentful is not good.

\section{Increased hostility towards the academic}

There were four students who did not make statements about resentment of monit oring or being split from a group, but wrote what could only be described as hostile evaluations. These students may well have been students who were split from a group or who resented monitoring, but that is not known with any certainty. However, given that other students gave excellent evaluations and that the academic involved had taught this particular course for about seven years and had taught at the same university for twenty years and had always had very positive evaluations and never a sign of such hostility, one can assume the hostility had something to do with the MG strategy!

\section{Discussion and a New Implementation}

While it is true that it is rewarding to have good, hard working, students tell you that they are very happy with how the group work and marking was managed compared with how it is managed in other courses, it is not pleasant to have even a few out of many students being so resentful or even hostile. Any future implementations of the MG strategy would need to be modified to help lessen such resentment and hostility.

The same course as that used to implement the MG strategy has just been run again,though this time in intense, summer, 3-week mode for a class of just 20 students. This course provided an opportunity to try to address some of the problems with the MG strategy. Consideration of the 
running of the summer intense mode offering can act as a platform for discussing the regular mode offering.

It was apparent when at tempting to implement the MG strategy that splitting students into groups according to marks on an initial assignment was not viable. It was also clearthat fewer problems would occur if students had more control over who was in their group. At the same time, past experience suggests that allowing students to choose their own group members can lead to problems; such as groups with limited perspective (Jalajas \& Sutton, 1984; Muller, 1989) and groups consisting of students no one else wants (Beaman \& Stolz, 1992). Thus, for the summer offering, students were first given a 'speed dating' session in which they moved from person to person every two minutes, getting to know them. They were then asked to number (in order of preference) at least 5 students they would like to have in their group (see Hansen \& Hansen, 2007 for another example of 'speed dating' to help form groups). This worked well and is probably a very good compromise between self-selecting and randomly selected groups. On the academic's part, the main problem is that it can be difficult to know how to satisfy everyone. It would be easier if students were asked to list, perhaps, at least 8 people they would like to work with. As for the students in the summer offering where 'speed dating' was used, they all seemed happy when told of the group memberships.

It was also clear from the MG implementation discussed in this paper that the monitoring of groups by meeting with each group most weeks and discussing whether there were problems was sometimes resented. It was decided in the summer offering to monitor groups less obviously. Thus, instead of meeting each group most weeks, each group member submitted a daily report, out lining how the group had met, who was present, what the group had done and why, and what they personally had done. Each report was worth $2 \%$ of the course. There were no complaints about these reports or the monitoring of the groups. Of course, there were only 20 students taking the summer course, so any conclusion must be tent at ive, but the "daily" (or "weekly") report for $2 \%$ marks is certainly worth trying with a large class taught in a regular 13-week mode.

Was there a need to split groups in the summer offering? Yes. Due to logistical reasons, one "group" consisted of just two people, each of whom had put each other as their first choice. It turned out that one of the students was very high achieving and hard working, the other less so. Within two days there was a problem with the former student complaining about the latter and saying he was very stressed about the situation. It was obvious they had to be split. They then worked by themselves, without penalty, and were quite happy to do so. Unfortunately, this meant they were no longer working in a group environment. Probably no group should begin with just two students, but unfort unately due to some logistical problems relating to the summer offering this was hard to avoid. In a larger class, in regular mode, it should be able to be avoided.

Were there any non-workers in the summer offering? Yes. There was one student who was not contribut ing much to his group. This was obvious by his not coming to class for 2 days in a row and by his name being absent from group meetings in the daily reports. When he appeared in class he was warned that he needed to turn up to class and meetings or would risk having to do the project by himself and incurring a $10 \%$ penalty. He decided to withdraw from the class. In circumstances where there are no daily reports or the opport unity to withdraw a student from a group and penalise them, such a student may well have attended the occasional meeting and class and survived as a 'free passenger'. He may have realised that being a 'free passenger' was not possible and therefore withdrew.

As with the initial implementation of the MG strategy, there were no group marks, but only individual marks for each person's part in the group presentation and for the individual report. Were all students happy with their marks in the summer offering? At this stage, students who took the summer mode are only aware of a general grade for their presentation. One student seemed a 
little perplexed by the notion that group members could get different marks, presumably because he has not encountered that before. He was told that if students seem to have a better grasp of the rationale behind the interface design or could explain it better than others, then they would get more marks. This was a student who received the lowest mark in his group, although in fact there was very little difference between the top and the bottom mark and they were all somewhere in the Distinction grade.

Overall, the second implementation of the MG strategy was better than the first. Further, it was once again satisfying to see students get the marks they deserved and also to see how students working in groups of differing ability could sometimes lead to a surprising amount of effort put in by students who had 'lifted their game' and were achieving great satisfaction from their efforts.

\section{What Still Needs to be Done to Refine the MG Strategy?}

The replacement of weekly meetings with short written reports was very successful and should be continued. Not only was it a simple way of monit oring groups without students feeling like 'children', but it provided a way of giving quick feedback about the processes students were using to design their interfaces.

The 'speed dating' was quite successful and worth pursuing. Not only did the students feel they had some control who they worked with, but it provided a good opport unity for students to meet new students and forge new friendships.

The use of individual marks seems to be appreciated. However, there probably needs to be more discussion about why students in a group might receive different marks and what could lead to the differing marks. This could be done while discussing real work situations; such as two workers giving present ations to their supervisor or a client, or explaining something to a new work colleague, and one worker doing a better job than the other. Whether it is because one worker understands or knows more than the other, or whether one can just present the material better than the other, the former is still more valued as an employee.

The primary problem remains with managing the groups. Apart from having 'speed dating' to allow students some control over who they have in a group and having the regular written reports, a key to increased opportunity for group success is having at least four in a group, with five being even safer. Even if a group of four or five is split, each student at least has the experience of working with someone else.

\section{Conclusion}

In a large class of about 150 students, when there is group work, as in any real world situation, it will probably always be the case that some problem arises. The MG strategy does seem to give relief to hard working students as they can get the mark they deserve, while still having the benefit of working with a group. They know that they can get the mark they deserve and that if another student is not giving all their effort then they may be removed from the group. Stress for them is relieved. For students who would normally be 'free passengers,' the situation might not be as good. While it is tempting to say 'too bad,' we need totry to motivate these students more. That, in the end, would be a way of avoiding problems. Perhaps that is something that must be kept in more in mind.

One could wonder whether we should just give up on providing students with group projects. Such a solution would mean that students miss out. When things went well with groups where the MG strategy was implemented, some marvellous things happened. Apart from good students feeling satisfied and less stressed, there were many instances of lesser students 'lifting their 
game' and showing great pride in their accomplishment, some receiving grades they had never received before, and due to their own effort, not simply by riding on the 'coat-tails' of others.

\section{References}

Beaman, R., \& Stolz, P. G. (1992). A method to the madness: The selection of student public relations groups. Public Relations Review, 18, 91-96.

Cohen, E. (1994). Collaborative learning: Higher education, interdependence, and the authority of knowledge. Baltimore: John Hopkins University Press.

Van Der Vyver, G., \& Lane, M. (2003). Using a team-based approach in an IS course: An empirical study. Journal of Information Technology Education, 2, 393 - 406. Retrieved from http://iite.org/documents/Vol2/v2p393-406-44.pdf

Ford, M., \& Morice, J. (2003). How fair are group assignments? A survey of students and faculty and a modest proposal. Journal of Information Technology Education, 2, 367 - 378. Retrieved from http://jite.org/documents/Vol2/v2p367-378-42.pdf

Goffee, R., \& Jones, G. (1998). The character of a corporation: How your company's culture can make or break your business. London: Harper Collins Business.

Hansen, R. S., \& Hansen, K. (2007). The student experience in speed teaming: A new approach to team fo rmation. Proceedings of ABR \& TLC Conference, Hawaii, 2007.

Hasan, B., \& Ali, J. (2007). An empirical examination of factors affecting group effectiveness in information systems projects. Decision Sciences Journal of Innovative Education, 5, 229- 243.

Jalajas, D. S., \& Sutton, R. I. (1984). Feuds in student groups: Coping with whiners, martyrs, saboteurs, bullies, and deadbeats. Organizational Behavior Teaching Review, 9, 217 - 227.

Johnson, D., \& Johnson, R. (1996). Conflict resolution and peer mediation programs in elementary and secondary schools: a review of the research. Review of Educational Research, 66, 459-506.

Koppenhaver, G., \& Shrader, C. (2003). Structuring the classroom for performan ce: Cooperative learning with instructor-assigned teams. Decision Sciences Journal of Innovative Education, 1, 1-22.

Muller, T. E. (1989). Assigning students to groups for class projects: An exploratory test of two methods. Decision Sciences, 20, 623-634.

Williams, D. L., Beard, J. D., \& Rymer, J. (1991). Team projects: Achieving their full potential. Journal of Marketing Education, 13, 45 - 53. 


\section{Biographies}

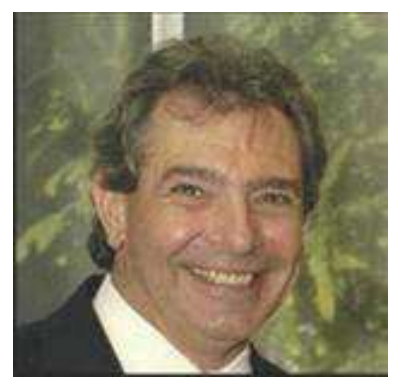

Dr. Tony Je wels is a senior lecturer within the School of Information Systems at Queensland University of Technology, Brisbane, coordinating IT project management units. An IT professional for over 30 years, he has worked in a variety of roles on many leading edge projects throughout the world. His practical experience combined with academic qualifications in business management and information technology provides students at both undergraduate and post graduate level with real world perspectives of life within the IT sector.

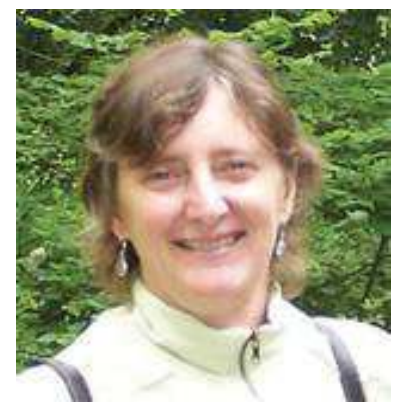

Dr. Marilyn Ford is an associate professor in the School of Information and Communication Technology and a member of the Applied Cognitive Neuroscience Research Centre at Griffith University. She has publications in the areas of reasoning, education, and sentence perception and production. 